\title{
Analisa Geoelectrical Strike Metode AMT untuk Identifikasi Awal Potensi Sistem Panas Bumi di Daerah Gunung Pancar Bogor Jawa Barat
}

\author{
Wahyu Hidayat ${ }^{1}$, Hafiz Hamdalah ${ }^{2)}$, Hana Aulia K. ${ }^{3)}$ \\ 1,2,3) Jurusan Teknik Geofisika, Universitas Pembangunan Nasional "Veteran" Yogyakarta \\ Coresponding author email: wahyu.machmud@upnyk.ac.id
}

\begin{abstract}
Abstrak
Satu daerah yang diduga terdapat sistem panasbumi adalah daerah Gunung Pancar, Bogor, Jawa Barat. Beberapa mata air panas yang muncul di sekitar daerah penelitian memperkuat dugaan adanya sistem panasbumi di daerah tersebut. Metode geofisika yang dapat digunakan untuk mengidentifikasi sistem panasbumi adalah Metode Audio Magnetotelurik (AMT). Penelitian ini menggunakan metode AMT untuk mendapatkan gambaran bawah permukaan dengan pemodelan 1D dan pemodelan 2D. Pengolahan data dilakukan dengan menggunakan software MT Editor, Interpex, dan Petrel. Geoelectrical strike digunakan untuk mengetahui arah strike bawah permukaan dimana nilai kontras resistivitasnya dapat diindikasikan sebagai gangguan geologi. Data yang digunakan adalah data angle dan radius pada software MT Editor. Sementara software yang digunakan untuk membuat diagram roset adalah software GeoRose. Hasil pemodelan menunjukkan adanya komponen panasbumi berupa claycap $(1 \Omega . m-10 \Omega . m)$ dan reservoir $(10 \Omega . m-20$ $\Omega . \mathrm{m})$ pada kedalaman $300 \mathrm{~m}$ hingga $2000 \mathrm{~m}$. Lapisan young sedimentary rock diinterpretasikan sebagai zona aliran air panas dengan nilai tahanan jenis sebesar $10 \Omega . \mathrm{m}-100 \Omega$.m. Sistem panasbumi di daerah penelitian diduga dikontrol oleh struktur geologi berupa sesar mendatar, antiklin, dan sinklin yang berkembang di bagian timurlaut daerah penelitian.
\end{abstract}

Kata Kunci : Audio-Magnetotelluric, Geoelectircal Strike, Sistem Panasbumi

\begin{abstract}
Abstrack
The areas that possibly had geothermal system is Mount Pancar, Bogor, West Java. There are several hot springs found around the study area. The geophysical method that can be used to identify the geothermal system and geological structure is the Audio-Magnetotelluric Method (AMT). AMT method is used to obtain subsurface overview with $1 D$ modeling and $2 D$ modeling. Data processing is done by using MT Editor, Interpex, and Petrel software. Geoelectrical strike is used to determine the direction of the subsurface strike by resistivity value. The most dominant angle and radius data from software MT Editor is used to make rosette diagram to show the geoelectrical strike. The results of $1 D$ modeling showed the geothermal component such as claycap (1 S.m - $10 \Omega . m$ ) and reservoir $(10 \Omega . m-20 \Omega . m)$ at a depth of $300 \mathrm{~m}$ to $2000 \mathrm{~m}$. The young sedimentary rock layer is interpreted as a discharge zone with a resistance value of $10 \Omega . m-100 \Omega . m$. The geothermal systems in the study area might be controlled by geological structures in the northeast of the study area.
\end{abstract}

Keywords: Audio-Magnetotelluric, Geoelectrical Strike, Geothermal Systems. 


\section{Pendahuluan}

Pelelehan zona subduksi akan menghasilkan magma yang merupakan sumber utama dari suatu sistem panasbumi. Produk hasil subduksi tersebut yang menyebabkan Indonesia menjadi salah satu negara potensi panasbumi terbesar di dunia. Salah satu daerah yang diduga terdapat sistem panasbumi adalah daerah Gunung Pancar, Bogor, Jawa Barat. Gunung Pancar merupakan intrusi andesit porfiritik di Formasi Jatiluhur. Metode geofisika yang dapat digunakan untuk memastikan adanya potensi panasbumi di daerah Gunung Pancar, Bogor, Jawa Barat adalah metode Audio Magnetotelurik (AMT). Penelitian ini dimaksudkan untuk mendapatkan gambaran bawah permukaan dengan melakukan pemodelan $1 \mathrm{D}$ dan pemodelan 2D, mengevaluasi keberadaan sistem panasbumi, serta menduga keberadaan struktur berdasarkan geoelectrical strike.

Metode AMT merupakan metode geofisika yang bersifat pasif karena memanfaatkan gelombang elektromagnetik untuk mengetahui nilai tahanan jenis batuan di bawah permukaan. Metode ini merekam data dengan frekuensi yang tinggi $(>1$ $\mathrm{Hz}$ ) (Unsworth, 2013) karena bersumber dari aktivitas petir di ionosfer. Metode Magnetotulerik (MT) ini mengukur komponen medan listrik (E) dan medan magnet $(\mathrm{H})$ sebagai respon dipole alam. Salah satu asumsi dasar dalam memahami induksi medan elektromagnet adalah memenuhi persamaan Maxwell dalam domain frekuensi pada medium homogen isotropis (Simpson and Bahr, 2005). Persamaan Maxwell adalah sebagai berikut:

$$
\begin{aligned}
& \nabla \times \vec{E}=-\frac{\partial B}{\partial t} \\
& \nabla \times \vec{H}=\vec{J}+\frac{\partial D}{\partial t} \\
& \nabla \times \vec{D}=q \\
& \nabla \times \vec{B}=-\frac{\partial B}{\partial t}
\end{aligned}
$$

Rasio antara variasi medan listrik (E) dan medan magnet $(\mathrm{H})$ menghasilkan suatu besaran kompleks (impedansi) yang menggambarkan penetrasi medan elektromagnetik ke dalam bumi yang ditulis sebagai berikut:

$$
\vec{Z}_{x y}=\frac{\vec{E}_{x}}{\vec{H}_{y}}
$$

Penetrasi kedalaman medan elektromag-netik di bawah permukaan bergantung dari periode elektromagnetik sounding dan struktur konduktivitas material bumi. Dalam besaran impedansi terdapat informasi mengenai resistivitas yang merupakan parameter yang diukur pada metode AMT (Unsworth, 2013) Secara matematis resistivitas dapat dituliskan:

$$
\rho=\frac{1}{\sigma}=\frac{|\overrightarrow{\vec{E}}|^{2}}{\mu \omega}=\frac{1}{2 \pi \mu f}|\vec{Z}|^{2}
$$

\section{Geologi Daerah Penelitian}

Pulau Jawa terletak diantara pertemuan lempeng Eurasia dan lempeng Australia. Hal tersebut menyebabkan terdapat banyak struktur yang berkembang di Pulau Jawa, termasuk di Gunung Pancar. Struktur yang berkembang di bagian timurlaut Gunung Pancar dapat dikatakan kompleks. Di bagian timurlaut Gunung Pancar dapat ditemukan lipatan antiklin dan sinklin yang berorientasi dari tenggara - baratlaut. Lipatan ini dibatasi oleh sesar geser dibagian barat dan timurnya. Selain itu terdapat struktur berupa sesar mendatar dengan orientasi timurlaut - baratdaya yang memotong sumbu lipatan, membujur melalui sekitar Warung-barang dan Sileuri. Umumnya struktur berkembang baik pada batuan andesit yang berumur Kuarter. Proses tektonik yang terjadi pada akhir Miosen Akhir menghasilkan dua pola struktur yang berbeda yaitu pengangkatan yang kemudian diikuti oleh terobosan batuan andesit.

\section{Manifestasi Gunung Pancar}

Secara administratif Gunung Pancar terletak di Kabupaten Bogor, Provinsi Jawa Barat dan secara geografis terletak antara $106^{\circ} 90^{\prime} 83,638^{\prime \prime}$ BB - 106 $93^{\prime} 1039^{\prime \prime}$ BT dan 6 ${ }^{\circ} 58^{\prime} 43,138^{\prime \prime}$ LU 6 59'50,794" LS dengan ketinggian 871mdpl. Berdasarkan fisiografi daerah Jawa Barat oleh Van Bemmelen (1949), Gunung Pancar termasuk ke dalam Zona Bogor. Zona Bogor merupakan perbukitan lipatan yang terbentuk dari batuan sedimen tersier laut dalam membentuk suatu Antiklonorium, yaitu antiklin besar yang terdiri dari beberapa lipatan (fold) yang lebih kecil.

Gunung Pancar didominasi oleh batuan vulkanik kuarter hasil asosiasi dimana Gunung Pancar merupakan puncak parasit (parasitic cone) dari Gunung Gede Pangrango yang terletak di sebelah tenggara Gunung Pancar. Meskipun tidak ditemukan manifestasi panasbumi di atas Gunung Pancar, manifestasi terdistribusi di daerah Timur dan Utara Gunung Pancar. Manifestasi tersebut berupa adanya alterasi dan hot spring yang 
dikontrol oleh fault dan dikenal sebagai Kawah Merah, Kawah Hitam dan Kawah Putih. Hal ini menandakan bahwa sistem panasbumi di daerah Gunung Pancar diklasifikasikan ke dalam sistem panasbumi low to moderate temperature (Daud, dkk. , 2015).

\section{Metodologi \\ Pengolahan Data}

Pengolahan data bertujuan untuk mendapatkan gambaran bawah permukaan dengan menggunakan pemodelan 1D dan pemodelan 2D. Pengolahan data dilakukan menggunakan software MT Editor, Interpex, serta Petrel. Geoelectrical strike didapatkan dari nilai angle dan radius pada software MT Editor. Angle dengan nilai radius terbesar pada setiap frekuensi diinput ke software Georose untuk mendapatkan sudut dominan dari geoelectrical strike.

\section{Seleksi Cross Power}

Cross Power merupakan kumpulan data parsial MT di setiap frekuensi yang dirata-ratakan sehingga menghasilkan titik dengan bobot yang berbeda-beda pada kurva resistivitas dan fasa. Seleksi pembobotan dilakukan dengan memberikan bobot relatif pada data yang ditentukan oleh data berkualitas baik.
Model 1D merupakan teknik untuk mengetahui variasi tahanan jenis terhadap kedalaman. Pemodelan 1D dilakukan dengan menggunakan inversi Bostick dan inversi Occam. Pemodelan 2D dilakukan dengan mengkorelasi hasil pemodelan 1D.

\section{Geoelectrical Strike}

Geoelectrical strike adalah arah dimana nilai tahanan jenisnya selalu konstan (Khyzhnyak, 2014). Geoelectrical strike menunjukkan arah dimana nilai elemen diagonal dari tensor impedansi minimal (Khyznyak, 2014).

\section{Hasil Dan Pembahasan \\ Hasil Seleksi Cross Power}

Kurva tahanan jenis terhadap frekuensi AMT 07 memperlihatkan respon antara pola TE dan TM dimana kedua kurva tersebut saling memotong (Cross). Hal ini menunjukkan adanya kontras resistivitas di frekuensi $10 \mathrm{~Hz}$ yang mengindikasi adanya gejala geologi, berupa struktur. Meskipun begitu, hal tersebut harus dikaji ulang dengan dikorelasikan dengan hasil pemodel-an 1D dan 2D ditinjukkan pada Gambar 1. Semen-tara pada kurva fasa terhadap frekuensi kedua kurva saling berkebalikan dengan interval yang cukup jauh.

\section{Pemodelan 1D dan Pemodelan 2D}

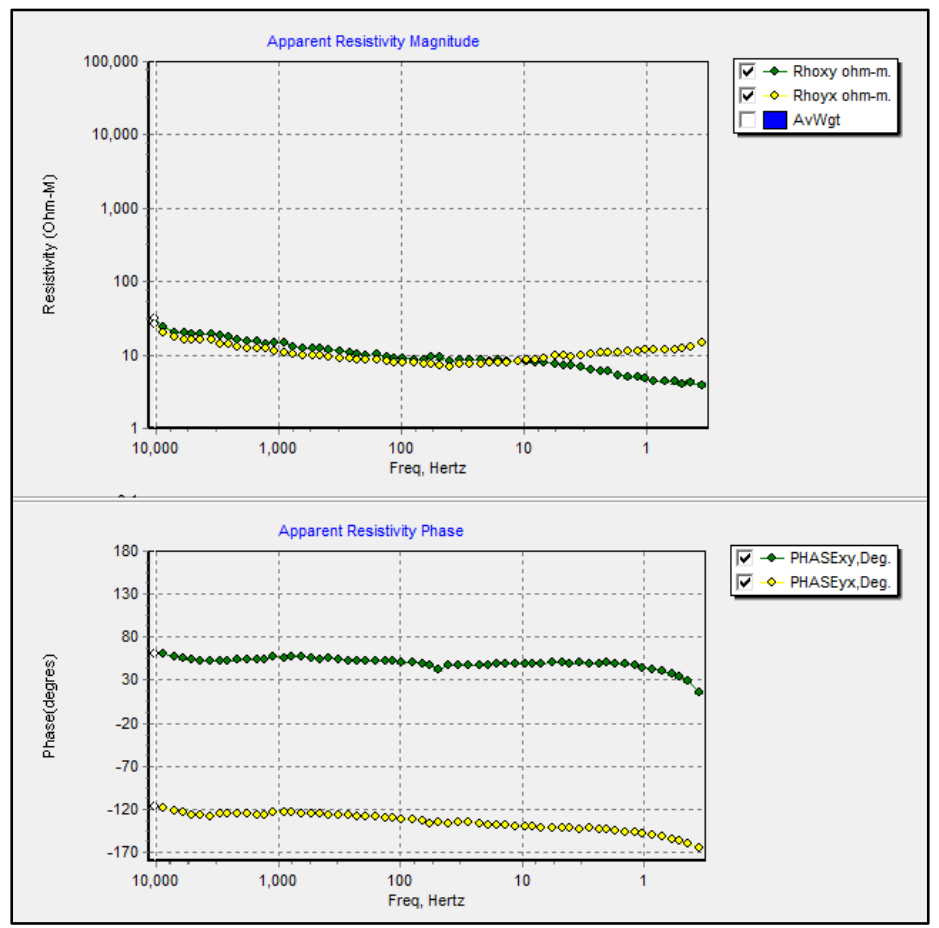

Gambar 1. Kurva MT Data AMT 07 


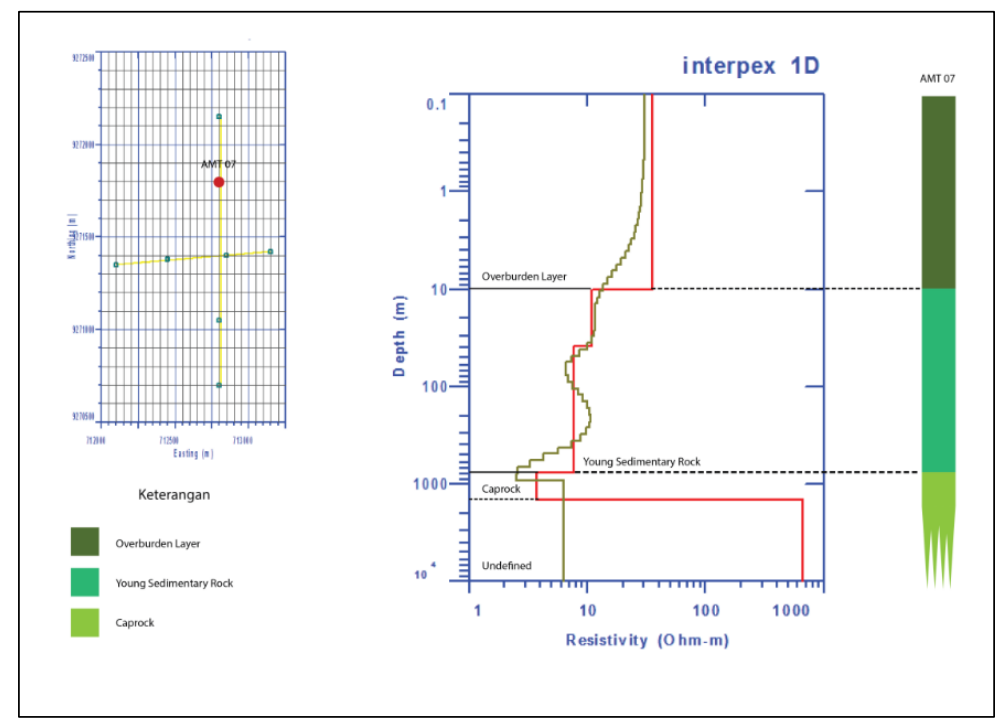

Gambar 2. Hasil Pengolahan Software Interpex Titik AMT 07

Nilai resistivitas 37 S.m dengan ketebalan lapisan $10 \mathrm{~m}$ diinterpretasikan sebagai overburden layer. Nilai yang konduktif pada lapisan kedua menunjukkan adanya claycap dengan nilai resistivitas 7,7 $\Omega . \mathrm{m}-10,9 \Omega . \mathrm{m}$ dan ketebalan lapisan $758 \mathrm{~m}$. Claycap terbentuk akibat adanya proses alterasi dari lapisan di atasnya ditunjukkan pada Gambar 2. Dari penelitian terdahulu (Daud, 2015) diketahui bahwa terjadi alterasi argilik di area penelitian. Proses alterasi argilik umumnya terjadi pada batuan permeabel dengan porositas yang tinggi dan mengubahnya menjadi batuan impermeabel akibat rusaknya unsur potasium, kalsium dan magnesium. Tipe argilik umumnya terbentuk pada temperatur $100-300^{\circ} \mathrm{C}$ (Pirajno, 1992), fluida asam hingga netral dan salinitas yang rendah. Alterasi agrilik memunculkan mineral clay seperti kaolinit, smektit, monmorilonit, dan ilit (Guilbert and Park, 1986).

\section{Korelasi 1D Lintasan 1 dan 2.}

Hasil korelasi 1D lintasan 1 menunjukkan komponen sistem panasbumi berbentuk seperti graben yang ditandai dengan adanya claycap serta reservoir pada AMT 01 dan AMT 04 dapat dilihat pada gambar 3. Reservoir yang terdapat di area Gunung Pancar berupa batuan sedimen permeabel sebesar $10 \Omega \mathrm{m}-100 \Omega \mathrm{m}$. Lapisan young sedimentary rock merupakan Formasi Jatiluhur (Tmj) yang diduga zona aliran air panas.

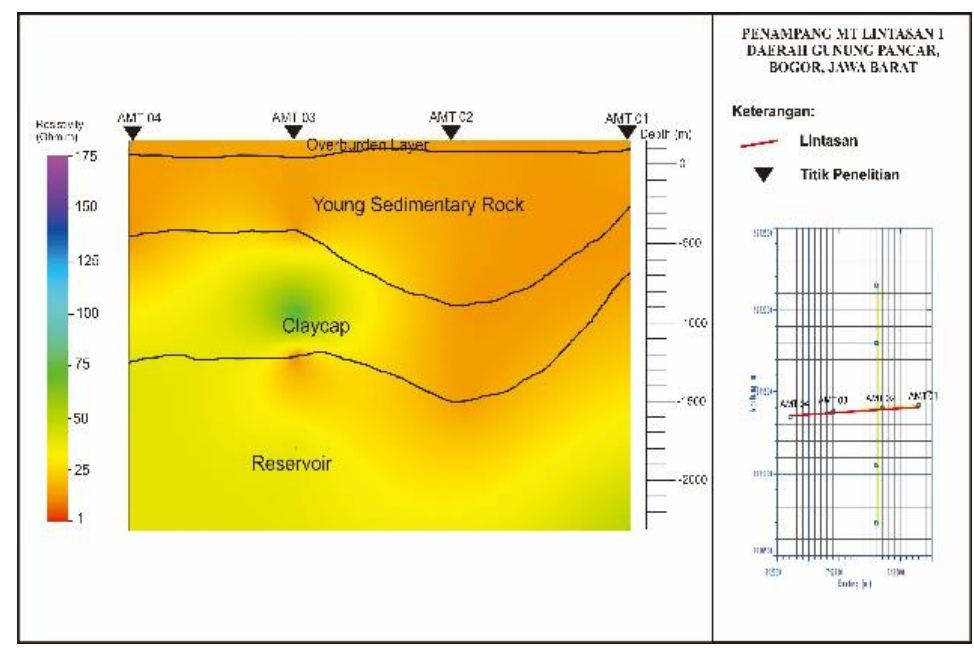

Gambar 3. Hasil Korelasi 1D Lintasan 1 dengan Software Petrel

Lintasan 2 terdiri dari titik AMT 05, AMT 06, AMT 07, dan AMT 08 yang melintang dari utara ke selatan dengan jarak antar titik $1 \mathrm{~km}$ dapat ditunjukkan pada gambar 4. Terobosan andesit ditemukan pada lintasan 2, yaitu pada AMT 05 dan terdapat bongkah pada AMT 06 sedalam $10 \mathrm{~m}$. 
Nilai tahanan jenis andesit di daerah Gunung Pancar, Bogor, Jawa Barat sebesar $100 \Omega \mathrm{m}->400$ $\Omega \mathrm{m}$. Menurut data geologi (Effendi dan Hermanto, 1998), terobosan andesit terbentuk pada masa Miosen Akhir bersamaan dengan proses uplift yang mengintrusi Formasi Jatiluhur berumur Miosen Awal. Andesit di daerah Gunung Pancar, Bogor, Jawa Barat mengandung mineral - mineral seperti hornblende, augit, hipersten, dan oligoklas-andesin yang membentuk plug dan dike.

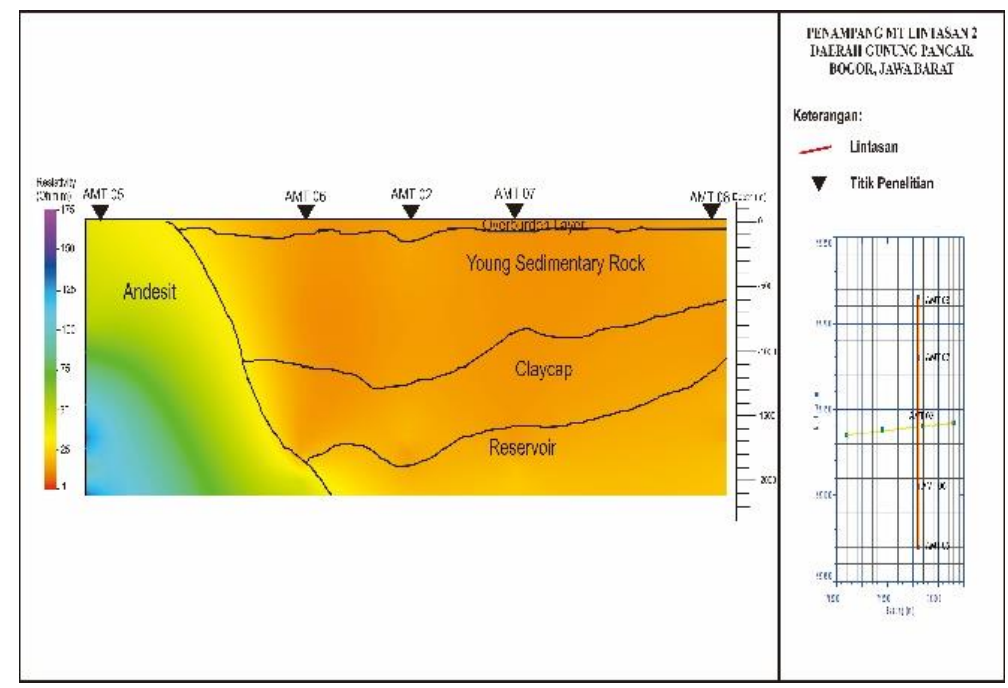

Gambar 4. Hasil Korelasi 1D Lintasan 2 dengan Software Petrel

\section{Geoelectrical Strike}

Geoelectrical strike adalah suatu arah dimana nilai konduktivitasnya selalu konstan. Nilai strike didapatkan dari nilai maksimum elemen diagonal (Zxy) dari tensor impedansi. Hal ini dapat menunjukkan adanya struktur geologi maupun aliran - aliran fluida geothermal (Khyzhnyak, 2014). Nilai geoelectrical strike tidak selalu sama dengan geological strike, tergantung pada pola tahanan jenis permukaan bawah permukaan.

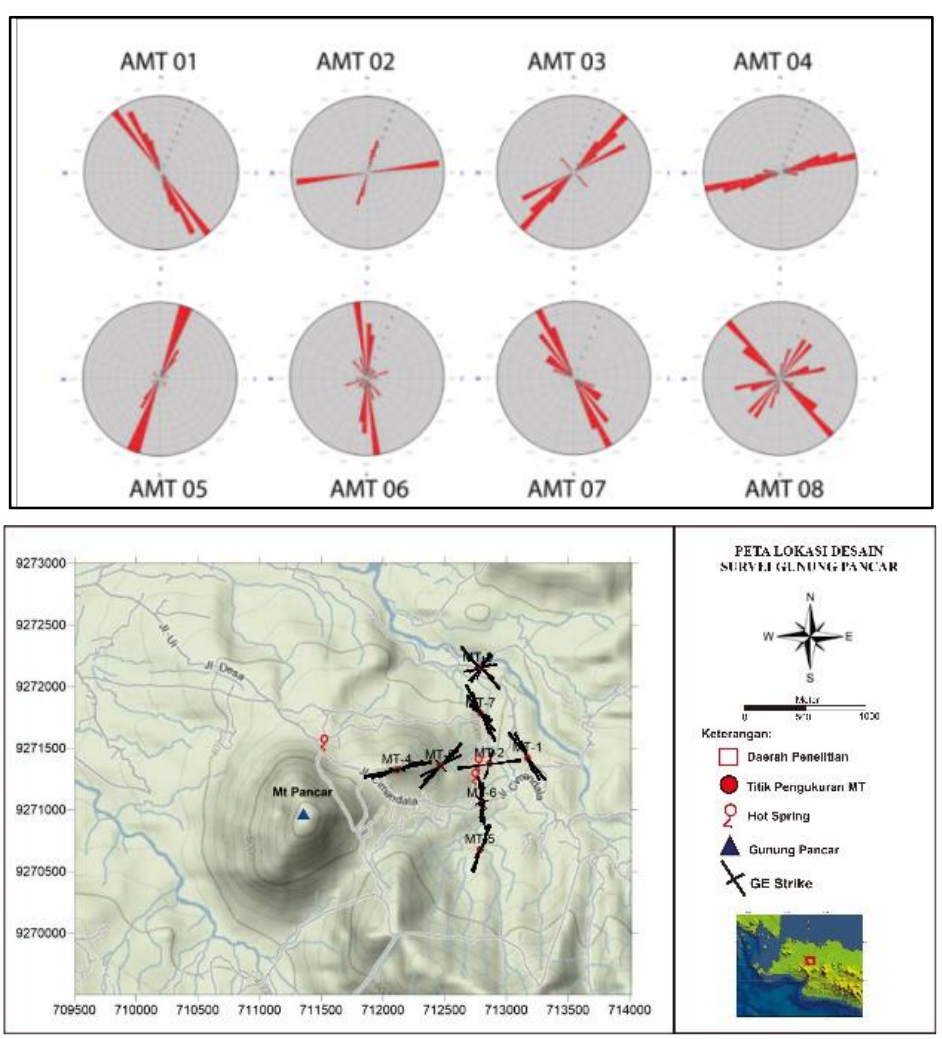

Gambar 5. Hasil Plot Diagram Roset Seluruh Frekuensi 
AMT 01, AMT 07, dan AMT 08 menunjukkan arah dominan $\mathrm{N} 135^{\circ} \mathrm{E}$ hingga $\mathrm{N} 150^{\circ} \mathrm{E}$ yang seluruhnya berorientasi ke tenggara baratlaut. AMT 02 dan AMT 04 berorientasi kearah timur - barat dengan sudut strike masing -

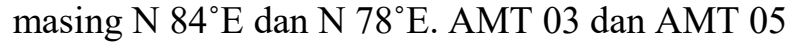
dengan arah strike dominan $\mathrm{N} 21^{\circ} \mathrm{E}$ dan $\mathrm{N} 42^{\circ} \mathrm{E}$ berorientasi timurlaut - baratdaya. Perbedaan sudut strike yang sangat signifikan pada lintasan 1 menunjukkan adanya struktur antara AMT 01 dan AMT 02. Sementara pada AMT 05 dan AMT 06, nilai strike yang signifikan disebabkan oleh adanya terobosan andesit di titik AMT 05 ditunjukkan pada Gambar 5.

Tabel 1. Nilai Maksimum $Z_{x y}$ Seluruh Titik

\begin{tabular}{|c|c|}
\hline STA & Angle \\
\hline 1 & $144^{\circ}$ \\
\hline 2 & $84^{\circ}$ \\
\hline 3 & $42^{\circ}$ \\
\hline 4 & $78^{\circ}$ \\
\hline 5 & $21^{\circ}$ \\
\hline 6 & $174^{\circ}$ \\
\hline 7 & $150^{\circ}$ \\
\hline 8 & $135^{\circ}$ \\
\hline
\end{tabular}

Data MT cenderung memiliki arah strike tenggara - baratlaut dan timurlaut - baratdaya. Apabila dikorelasi dengan data geologi di daerah penelitian terdapat adanya gangguan geologi berupa struktur patahan mendatar dengan arah timurlaut baratdaya yang membatasi antiklin dan sinklin dengan orientasi tenggara - baratlaut, sementara orientasi timur - barat diinterpretasikan sebagai sesar minor yang berkembang di area penelitian. Hasil korelasi data geofisika terdahulu menunjukkan adanya struktur berupa graben yang memperkuat dugaan adanya hotspring di daerah penelitian dikontrol oleh sesar mendatar.

\section{Kesimpulan}

Berdasarkan hasil pengolahan dan interpretasi pada penelitian di daerah Gunung Pancar, Bogor, Jawa Barat dengan menggunakan metode Magnetotelurik dapat disimpulkan bahwa:

1. Hasil pemodelan 1D menunjukkan adanya komponen sistem panasbumi berupa claycap (1 $\Omega . \mathrm{m}-10 \Omega . \mathrm{m})$ dan reservoir (10 $\Omega . \mathrm{m}-20$ $\Omega . m)$ pada kedalaman $300 \mathrm{~m}$ hingga $2000 \mathrm{~m}$. Lapisan young sedimentary rock diinterpretasikan sebagai zona aliran air panas dengan nilai tahanan jenis sebesar $10 \Omega . m-100 \Omega . m$. Beberapa titik menunjukkan adanya basement berupa batuan beku di bawah permukaan dengan nilai tahanan jenis yang relative besar, yaitu $(>100 \Omega . m)$.

2. Diduga kuat terdapat zona sistem panasbumi di daerah Gunung Pancar, Bogor, Jawa Barat yang dikontrol oleh sistem tektonik. Hal ini didukung oleh geoelectrical strike yang menunjukkan arah orientasi struktur berkembangya itu dominan kearah tenggara - baratlaut dengan sudut strike $\mathrm{N} 135^{\circ} \mathrm{E}$ hingga $\mathrm{N} 174^{\circ} \mathrm{E}$.

3. Hasil plot manual polar diagram memperlihatkan pola 2D, sementara hasil plot diagram roset menunjukkan arah geoelectrical strike. Pada lintasan 1, titik AMT 01 memiliki nilai strike sebesar $\mathrm{N} 144^{\circ} \mathrm{E}$, AMT 02 sebesar $\mathrm{N}$ $84^{\circ} \mathrm{E}$, AMT 03 sebesar $\mathrm{N} 42^{\circ} \mathrm{E}$, dan AMT 04 sebesar $\mathrm{N} 78^{\circ} \mathrm{E}$. Sementara pada lintasan 2 , titik AMT 05 memiliki sudut strike sebesar $\mathrm{N} 21^{\circ} \mathrm{E}$, AMT 06 sebesar $\mathrm{N} 174^{\circ} \mathrm{E}$, AMT 07 sebesar $\mathrm{N}$ $150^{\circ} \mathrm{E}$, dan AMT 08 sebesar $\mathrm{N} 135^{\circ} \mathrm{E}$.

\section{Daftar Pustaka}

Daud, Yunus., Rosyid, S., Suparno, S., Heditama, D.M., Nuqramadha, W.A., Fahmi, F., Pratama, S.A., Sulistyo, A. 2015. A Student Project Aimed to Investigate the Low to Moderate Temperature Geothermal System in Mt Pancar Area, Bogor (Indonesia) 
dalam Geophysics Field Camp (GFC). Geothermal Laboratory, Department of Physics, The University of Indonesia. Proceedings World Geothermal Congress.

Guilbert, John M. and C. F. Park, Jr., 1986. The Geology of Ore Deposits. W. H. Freeman.

Khyzhnyak, M., 2014. Geoelectric Strike And Its Application In Magnetotellurics. Faculty of Earth Science: University of Iceland.

Pirajno, F. 1992. Hydrothermal Mineral Deposits, Principles and Fundamental Concepts for the Exploration Geologist. Springer-Verlag. Berlin, Heidelberg, New York, London, Paris.
Simpson, F., dan Bahr, K., 2005. Practical Magnetotellurics. Cambridge University Press.

Unsworth, M., 2013. Theory of Magnetotelluric Over $1 D$ Earth. University of Alberta, Cana 